\title{
PRODUTIVIDADE $x$ VALOR AGREGADO NA MANUFATURA: UMA REVISÃO DA LITERATURA
}

\section{PRODUCTIVITY $x$ VALUE ADDED IN MANUFACTURING：A REVIEW}

${ }^{1}$ Wagner Boer; ${ }^{1}$ José Paulo Alves Fusco

${ }^{1}$ Faculdade de Engenharia de Bauru - FEB UNESP - Bauru - Brasil wagner.boer@embraer.com.br

\begin{abstract}
Resumo
O presente artigo propõe a investigação da adoção de programas de produtividade como vetor facilitador para formação do valor dos produtos que são ofertados ao mercado. Adicionalmente, o trabalho apresenta uma forma alternativa para visualização das relações de causa e efeito existentes.Para tanto, são examinados aspectos e contribuições de diversos autores, resultando ao final em um composto analítico que possa representar de forma adequada os aspectos avaliados. Ao final, o trabalho conclui que ainda existe considerável espaço para demonstrar que o valor agregado também é resultado da cultura organizacional. Além disso, pode-se perceber que existem inúmeras outras possibilidades de estudo, ainda não contempladas, que mereceriam maior aprofundamento em futuras pesquisas.
\end{abstract}

Palavras chave: Produtividade; Valor Agregado; Gestão da Manufatura.

\section{Introdução}

O ambiente dos negócios tem continuamente passado por diversos processos de mudanças muito rápidos. No entanto, essas mudanças são apenas partes da constante evolução nos aspectos social, econômico, tecnológico e, sobretudo, comportamental que as nações vêm experimentando. Elas proporcionam a contínua criação de um processo atualmente conhecido como globalização. A globalização tem ameaçado a sobrevivência das empresas em todo o mundo por diversos motivos:

- Velocidade na atualização dos produtos;

- Perda de competitividade devido a novos entrantes internacionais com preço baixo;

- Ineficiência dos equipamentos perante novas tecnologias empregadas pela concorrência;

- Emergência de sistemas normativos como virtuais barreiras de entrada no mercado internacional.

- Em um cenário desse tipo, empresas até então em posições aparentemente fortes, podem, 
devido às rápidas mudanças, ter a sua própria existência ameaçada.

Como conseqüência, alguns aspectos têm tido maior relevância ao servir como base nas tentativas de busca da sobrevivência por parte das empresas. Dentre eles observa-se, que:

As nações têm procurado se organizar em blocos econômicos;

Os mercados passaram a valorizar os bens e serviços além dos preços;

As empresas têm buscado a excelência com processos de melhoria;

Há uma busca intensa na melhoria do relacionamento entre empresa e mercado.

Dos estudos de Henderson (1989), é possível fazer uma comparação de como o mundo empresarial opera, do mesmo modo que o reino animal, ou seja, duas empresas que negociam os mesmos bens e serviços, no mesmo território, da mesma forma e com a mesma clientela, não podem coexistir igualmente. Cada empresa precisa ser diferente o bastante, para possuir uma vantagem única que permita lhe sobreviver. A base dessa observação relaciona-se com a biologia Darwiniana, segundo a qual onde “duas espécies não podem coexistir, se conseguem seu sustento de maneira idêntica”.

Sendo assim, se concluiu que a competição existe muito antes da estratégia, pois quando duas espécies competem por um mesmo recurso essencial, uma delas irá deslocar a outra.

Levando em conta a estratégia associada à habilidade de tomar decisões, quando as empresas as desenham buscam definir um conjunto de ações que as comprometam com objetivos e metas ao longo do tempo, de modo a melhorar sua posição competitiva.

O fato das empresas centrarem o foco em aspectos preponderantemente ligados à produtividade como forma de medida de eficiência, evidencia a necessidade de se procederem estudos adicionais que possam contribuir para complementar sua formação conceitual das empresas, porque a medida de maior consistência é a eficácia. Desse modo, pode-se ampliar outras opções de análise na exploração de seus negócios o potencial representado pelas múltiplas dimensões de eficiência e eficácia, mas de forma sustentável, no sentido de perpetuar o processo organizacional.

\section{A administração dos Sistemas de Operações}

Os processos de manufatura têm buscado responder com velocidade cada vez maior aos seus mercados, quando se compara às respostas obtidas há vinte anos atrás. Essa evolução deu -se em função da rápida mutação da economia para um processo globalizado, cujas características podem muitas vezes ser expressas em modelos de alta complexidade. A chamada “competitividade” é a resposta que as empresas buscam no sentido de manterem-se na vanguarda seus mercados.

Observa-se que a produção está deixando de ser tratada como um processo único nas organizações. Skinner (1969), por exemplo, propôs aspectos ou formas de interpretação da 
manufatura como uma ferramenta estratégica corporativa. Para as empresas alcançarem essa proposta, o autor sugere que a gestão deve ter inicio a partir da estratégia do negócio. Com isso, outros sistemas são requeridos para apoiar o processo produtivo, conforme Cavenaghi (2001) “com o reconhecimento da contribuição da manufatura, para o desempenho estratégico do negócio, a abordagem e os conceitos que envolvem essa área funcional foram reformulados”, onde o termo devido à nova amplitude transforma-se em “operações”. Um conjunto de operações passa então a ser tratado como “sistemas de operações”, integrando-se em um único, que é finalmente definido como sistema integrado de gestão.

Ainda, Cavenaghi (2001) afirma que, “o papel do administrador de operações é planejar e tomar decisões, visando buscar metas e objetivos na sua área de atuação que sejam alinhadas às metas e objetivos do negócio da organização”.

Segundo Slack (2002), dentro do projeto de um sistema de operações, deve-se continuamente levar em conta os aspectos de planejamento e controle, “qualquer operação requer planos e controle, mesmo que o grau de formalidade e os detalhes possam variar”.

Corrêa e Corrêa (2006) citam que o planejamento é de uma das questões centrais do tema da gestão de operações. Descrevem ainda que o termo representa a inércia intrínseca dos processos decisórios. Assim, é de grande importância que as fábricas tenham a capacidade de construir sistemas de produção eficientes e eficazes, no sentido de responder às rápidas flutuações de demanda de mercado com atitudes planejadas.

\section{Estratégia, Planejamento e Competitividade}

Conforme Porter (1986), as empresas descobriram diversas maneiras de se posicionar de forma competitiva. Segundo o autor, a melhor estratégia para as organizações é, em última análise, uma solução única que reflita suas circunstâncias particulares. Entretanto, num sentido mais amplo, ele define três estratégias competitivas genéricas: liderança em custo, diferenciação e enfoque, e finalmente leva em conta que um posicionamento estratégico pode ser constituído não só por uma dessas estratégias, mas de uma combinação delas.

Slack (2002), por sua vez afirma que, “uma estratégia é o padrão global de decisões e ações que posicionam a organização em seu ambiente e têm seu objetivo transformado em resultados de 
longo prazo”.

Fusco (2003), explica que as ações estratégicas são aquelas que: ”tem efeito abrangente, e por isso, são significativas na parte da organização à qual a estratégia se refere; definem a posição da organização relativamente ao seu ambiente; aproximam a organização de seus objetivos de longo prazo".

A estratégia pode ser dimensionada em função do tamanho da organização. Fusco (1997) estabelece que uma unidade de negócio pode ser visualizada como sendo uma unidade de planejamento, definida em termos de necessidades e oportunidades estratégicas.

Se a organização for uma corporação diversificada em unidades de negócios, a estratégia deverá incorporar o posicionamento do ambiente global em que elas atuam. E, desta forma, será composta de um nível de decisões corporativas. Com isto, as decisões poderão ser praticadas de acordo com condicionantes internos. Pontos fortes e fracos em conjunto com os condicionantes externos, ameaças e oportunidades. Assim, cada unidade de negócio estará elaborando sua estratégia levando em conta o seu ambiente e mercado específico alinhado aos objetivos corporativos. Finalmente, cada área funcional deverá traduzir suas estratégias funcionais e ações de modo a manter a sintonia com os objetivos da unidade de negócio e um nível superior da visão corporativa como um todo.

A identificação da estratégia em três níveis é recomendada por Hayes e Wheelright (1984), figura 1, no sentido de identificar os diferentes tipos de estratégias relacionadas com a gestão do negócio.

Figura 1 - Estratégia Corporativa

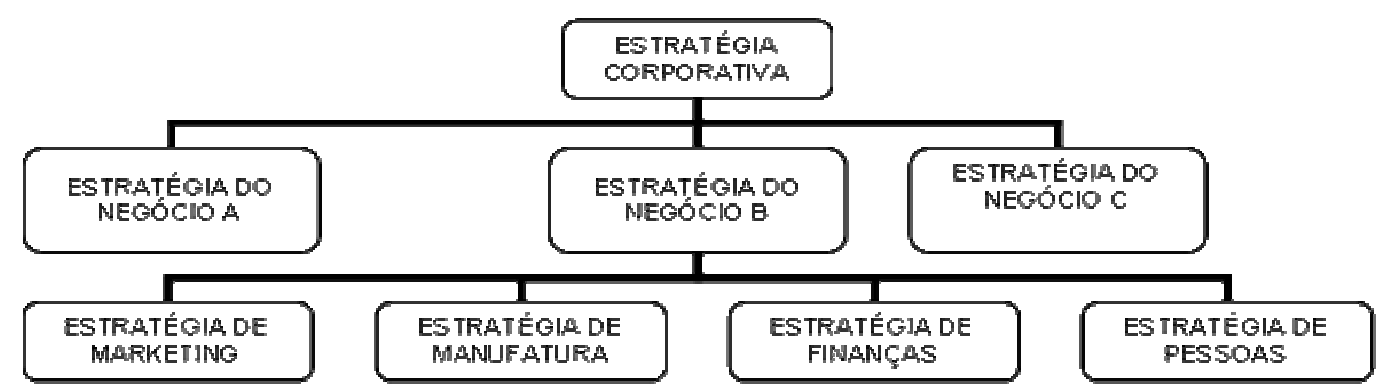

Fonte: Hayes e Wheelwright (1984,p 28)

Por sua vez, Porter (1998) afirma que a estratégia corporativa, para ser bem sucedida e agregar valor real, deve estar fundamentada em premissas que proporcionem às unidades de negócios, benefícios tangíveis, compensando assim o consumo de recursos. As premissas são:

- A competição ocorre no nível das unidades de negócios, ou seja, somente as unidades de negócios diversificadas das empresas é que competem. O autor afirma que "uma 
estratégia corporativa de sucesso deve nascer de uma estratégia competitiva e ainda deve poder reforçá-la”;

- A diversificação inevitavelmente acarretará aumento nos custos e restrições para as unidades de negócios;

- Os acionistas podem diversificar, selecionando negócios, perfis de risco ou ainda os investimentos.

Prosseguindo, Porter (1986) denominou estratégia competitiva como sendo a estratégia de uma unidade de negócio, que representa basicamente o desenvolvimento de uma estrutura para o modo no qual uma empresa irá competir.

Quando se explora uma “estratégia” relacionada à manufatura, defini-se como planejamento estratégico o modelo de decisão, unificado e integrador que revela o propósito organizacional em termos de valores, missão, objetivo, estratégias, metas e ações, com foco em priorizar a alocação de recursos, transformá-los e distribuir valores. O planejamento estratégico deve delimitar os domínios de atuação da organização e descrever as condições internas em que devem ocorrer as respostas ao ambiente externo e, ainda, a forma de modificá-las, com vistas ao fortalecimento da empresa, engajando todos os níveis da mesma.

Afirma Slack (2002), que a estratégia de produção deve ser claramente entendida como derivada e como sendo parte integrante da estratégia geral da empresa. O autor cita quatro perspectivas sobre estratégia da produção:

1. A estratégia de produção é direcionada de cima para baixo, refletindo e considerando em sua formulação o grupo de negócio que deseja alcançar.

2. As estratégias de produção “de baixo para cima”, juntamente com as melhorias de produção cumulativamente contribuem para a construção da estratégia geral.

3. A estratégia de produção precisa saber traduzir os requisitos e sentimentos do mercado em decisões da produção.

4. A estratégia de produção precisa saber explorar as capacidades dos recursos da produção para atendimento de nichos de mercado.

Para estabelecer os procedimentos de uma estratégia de produção, Slack (2002) relaciona dois métodos. O primeiro deles é a metodologia Hill, que segue a desejada abordagem de estabelecer uma conexão entre níveis diferentes de estratégia; é basicamente um procedimento composto em cinco etapas:

1. Objetivos da corporação, visando taxas de crescimento, lucratividade, retorno sobre ativos, fluxo de caixa e alavancagem financeira.

2. Estratégia de marketing, visando mercados e segmentos de produtos e serviços, gama de produtos e serviços, composto de especificações, volumes, padronização ou 
customização e taxa de inovação.

3. Atributos dos produtos e serviços que "ganham” os pedidos: preço, qualidade, velocidade de entrega, gama de produtos e serviços, projeto dos produtos ou dos serviços, imagem da marca e serviços de apoio.

4. Estratégia de ocupação com vistas à escolha do processo visando à tecnologia do processo, trade offs embutidos no processo, papel do inventário, capacidade e etc.

Estratégia de ocupação com vistas à infra-estrutura, visando apoio funcional, sistemas de planejamento e controle de produção, estruturação do trabalho, sistemas de pagamento e estrutura organizacional.

O segundo método foi desenvolvido por Platts e Gregory, onde os procedimentos passam por três estágios.

1. Envolve a compreensão da posição de mercado da organização através das avaliações das ameaças e oportunidades dentro do ambiente competitivo.

2. Envolve a avaliação das capacitações da operação com o propósito de avaliar a pratica das operações em função do desempenho estabelecido no estágio anterior.

3. Refere-se ao desenvolvimento de novas estratégias de produção.

Slack (2002) faz um comentário crítico a respeito dos dois modelos de processo de formulação da estratégia da produção em relação a expectativa criada por ele em sua obra. Ele afirma que a perspectiva que considera as estratégias emergentes e as perspectivas baseadas em recursos da produção não está completamente representada em nenhum dos dois modelos. Entretanto, ainda segundo o autor, os modelos instigam os gerentes a realizarem questionamentos estratégicos bastante úteis.

\section{Processo de Manufatura e o Planejamento e Controle de Produção}

Pode-se dizer que um dado processo de manufatura faz parte de um sistema maior denominado sistema de operações, ou seja, é uma função operacional das organizações que está sujeita à sistemática do planejamento como um todo.

Fusco (2003) descreve o sistema de produção como sendo "um conjunto de partes interrelacionadas que, quando acionadas, atuam sobre as entradas de acordo com padrões estabelecidos a priori para produzirem saídas”. Toda organização tem um sistema de operações para que possa produzir bens tangíveis, produtos de consumo geral ou ainda serviços.

As empresas, de modo geral, possuem um modelo de transformação que leva em conta os seguintes aspectos:

- Input - entradas. 
- Processo de transformação - está ligado diretamente à natureza dos inputs.

- Output - saídas.

No entanto, um sistema operacional de manufatura pode ser classificado conforme o fluxo de produto, dessa forma, esta classificação leva em conta três grupos principais com seus subtipos, são eles: produção contínua cujos subtipos são: contínua pura e contínua com diferenciação; produção intermitente cujos subtipos são: sob encomenda e repetitiva e por ultimo, produção para grandes projetos, conforme quadro 1.

Quadro 1 - Sistemas de produção e suas características

\begin{tabular}{|c|c|c|c|c|c|}
\hline $\begin{array}{l}\text { TIPO DE } \\
\text { PRODUÇÃOO }\end{array}$ & $\begin{array}{l}\text { NÚMERO DE } \\
\text { PRODUTOS OU } \\
\text { ATIVIDADES }\end{array}$ & $\begin{array}{c}\text { DIFERENCIAÇÄO } \\
\text { ENTRE PRODUTOS } \\
\text { E ATIVIDADES }\end{array}$ & DEMANDA & $\begin{array}{l}\text { VARIAÇÄO } \\
\text { NO } \\
\text { ROTEIRO }\end{array}$ & ESTOQUES \\
\hline CONTÍNUA PURA & UM & NENHUMA & GRANDE & NENHUMA & ELEVADOS \\
\hline $\begin{array}{l}\text { CONTÍNUA COM } \\
\text { DIFERENCIAÇÄO }\end{array}$ & POucos & POUCA & GRANDE & POUCA & ELEVADOS \\
\hline $\begin{array}{l}\text { INTERMITENTE } \\
\text { REPETITIVA }\end{array}$ & $\begin{array}{l}\text { MÉDIO / } \\
\text { GRANDE }\end{array}$ & MÉDIA / GRANDE & MÉDIA & $\begin{array}{l}\text { POUCA ' } \\
\text { MÉDIA }\end{array}$ & BAIXOS \\
\hline $\begin{array}{l}\text { INTERMITENTE } \\
\text { SOB } \\
\text { ENCOMENDA }\end{array}$ & GRANDE & GRANDE & $\begin{array}{l}\text { MÉDIA - } \\
\text { PEQUENA }\end{array}$ & $\begin{array}{l}\text { MÉDIA / } \\
\text { GRANDE }\end{array}$ & NENHUM \\
\hline $\begin{array}{l}\text { GRANDES } \\
\text { PROJETOS }\end{array}$ & MUITAS & GRANDE & PEQUENA & GRANDE & NENHUM \\
\hline
\end{tabular}

Fonte: Fusco e al. (2003, p 31).

O planejamento e controle da produção, (P.C.P.), deve ser visto como sendo parte de um sistema operacional que administra a produção, envolvendo um conjunto de atividades e decisões sobre o melhor emprego dos recursos produtivos. Essas atividades envolvem a interação, conhecimento, programação e provisão da capacidade instalada, dos recursos materiais, informacionais e humanos, de modo a atender as flutuações da demanda; contempla ainda, conhecimentos sobre os estoques e detalhes da cadeia de suprimentos e dos processos de transformação definindo tempos de espera, atravessamento e de set up (preparação), conferindo rapidez e precisão às ações corretivas necessárias para sanar eventuais desvios.

Corrêa e Corrêa (2006) estabelecem que o seqüenciamento, a programação de atividades e o controle são partes cruciais que, num contexto fabril, seguem a definição da American Production \& Inventory Control Society (APICS), referente ao que devem conter tais sistemas.

Um sistema emprega dados do chão de fábrica para manter e comunicar informações de situação corrente sobre ordens de fabricação e centros de trabalho. As maiores subfunções do Shop Floor Control, (SFC), são:

- Definir prioridades para cada ordem de produção;

- Manter informação sobre quantidades de estoque em processo; 
- Comunicar situação corrente de ordens de produção para gestão;

- Prover dados sobre saídas efetivas para suportar atividades de controle de capacidade produtiva;

- Prover informações de quantidade por local e por ordem de produção para efeito de controle de estoque em processo (operacional e contábil); e

- Prover a mensuração de eficiência, utilização e produtividade da força de trabalho e dos equipamentos.

Adicionalmente, Santoro e Fernandes (2005), estabelecem que as atividades de controle de fabricação podem ser auxiliadas por ferramentas automatizadas via sistemas computacionais. Elas poderão estar integradas aos sistemas de gestão Material Requirements Planning e Enterprise Resources Planning, ( MRP II / ERP), conforme o grau de prioridade dado ao P.C.P. pelas organizações. Os autores concluíram, ainda, que “o volume alocado de recursos a uma função deve ser compatível com o seu grau de prioridade e com o nível de suas necessidades”. O controle será mais prioritário quanto mais o sucesso do negócio depender de seu desempenho. Portanto, os mecanismos de P.C.P. serão mais complexos quanto mais complexos forem estes processos.

Bonney (2000) relata que no British Standard document BS 5192 Part 1:1993, a função de controle da produção é composta de três estágios relacionados entre si: programação, pedido e expedição. Além disso, estes estágios ocupam uma posição central na troca de informação entre os sistemas funcionais; vendas e mercado, projeto e desenvolvimento, suprimentos, financeiro e contabilidade, qualidade, engenharia de produção, distribuição e pessoal. Em suma, cada sistema de operações exige um modelo de P.C.P. adequado para garantir a alimentação e a saída do processo produtivo dentro das políticas estratégicas organizacionais.

Uma forma encontrada pelas empresas em exercer o controle da produção está ligada com o monitoramento da entrada e saída de ordens de produção, no processo produtivo, permitindo o controle sobre as quantidades de estoque em processo e o conhecimento do consumo da real capacidade disponível instalada. Dessa forma, como resultado, fica evidenciado que o processo de conclusão e liberação de ordens de produção e o controle do tempo de atravessamento no processo produtivo podem ser empregados como ferramentas de gestão, cujos resultados devem ser compartilhados com as equipes de produção como fatores estimuladores para o alcance de metas e objetivos.

\section{A relação entre produtividade, valor agregado e medidas de desempenho}

Segundo Contador (1996), no nível de operação a produtividade é a relação entre a 
quantidade produzida e os recursos a ela aplicada, no nível empresarial trata-se da relação entre o faturamento e os custos totais, e por último, no nível da nação trata-se da relação entre o Produto Nacional ou Interno e a população. Enfim, pode-se generalizar e dizer que é a relação entre o que é processado pelo necessário ou disponível ao processo.

Campos (1992), afirma que a produtividade é igual à taxa de valor agregado, pois se trata da relação do valor efetivamente produzido pelo valor consumido. O conceito considera que valor produzido corresponde à diferença entre o valor das saídas e o das entradas, sendo o valor consumido a soma dos valores gastos para formação do valor produzido.

Martins (1999) sugere três propostas para estruturação de um modelo de produtividade. São elas: abandono do conceito de operação (tarefa) em prol do conceito de evento; construção da cooperação por meio da comunicação ativa ao invés da comunicação retorcida e formal; participação e interpretação da formulação estratégica no lugar da tomada de decisão por meio do recorte hierárquico-funcional.

O sistema como cadeia de valor, tal qual descrito nos estudos de Porter (1986), demonstra uma série de fatores que se interrelacionam na busca da formação da margem excedente aos custos, cuja composição é:

- Atividades primárias: logística, operações, marketing e serviços tendo como base;

- Atividades de apoio: aquisição, desenvolvimento tecnológico, gestão de recursos humanos e infraestrutra da empresa e como conseqüência;

- Margem.

Segundo Martins (1999), de modo geral, calcula-se o valor agregado (ou valor adicionado) como sendo a diferença entre as vendas brutas e o total de insumos adquiridos de terceiros.

De outra maneira, Cardoso (2001) explica que valor agregado é a soma de toda a remuneração dos esforços consumidos nas atividades da empresa dentro de um determinado período.

Para De Luca (1998), o valor agregado total dos negócios é a soma do valor agregado da atividade produtiva e dos ganhos obtidos pelas aplicações dos recursos que geraram riqueza em outra empresa ou atividade. $\mathrm{O}$ autor prossegue afirmando que a distribuição do valor agregado apresenta separadamente as parcelas que destinam a remuneração de cada elemento que contribuiu para a sua formação: empregados; financiadores; governo e acionistas.

Os japoneses da Toyota aprenderam cedo a perceber que a relação preço e custo, até então explorada pelo mecanismo da produção em massa, deveria ser diferente, uma vez, que para eles, quem determina quanto custa o bem ou serviço são aqueles que se propõem a consumi-lo. No mesmo sentido, Parolini (1999), afirma que o valor é criado através de um sistema definido pela diferença entre o valor que o consumidor atribui a um bem ou serviço e o seu custo final, até o 
ponto de fornecimento.

Conceitualmente, um sistema de gestão é composto inicialmente pelos três aspectos que constroem a relação da manufatura; entradas, transformação e saídas. Compreende também o emprego de sistemas de informações, físicos e humanos, alimentados por capital e cultura. A função de um sistema de gestão é tornar efetivo o emprego dos recursos na obtenção de resultados para a organização no sentido mais amplo.

A produtividade é a forma de avaliação da eficácia do emprego do sistema de gestão, além do que ela origina-se do aspecto de que todo o negócio, em princípio, cria valor como conseqüência de suas atividades. Segundo Cardoso (2001), “cada atividade de um negócio representa um processo de agregação (adicionamento) de valor às entradas. Este valor é provado pela satisfação dos clientes no mercado. Nenhuma organização pode agregar valor independentemente das condições do mercado”.

Traduzir o valor agregado em atitude não é uma tarefa simples e puramente financeira, tratase de uma percepção de espírito. Para tanto, tomemos por base as empresas japonesas, as quais vêm desenvolvendo ao longo dos últimos cinqüenta anos uma interligação muito íntima com a produtividade, fazendo uso de indicadores adequados para a tomada de decisões. Neste caso, tais indicadores apóiam o desenvolvimento estratégico das empresas, em função de demonstrarem se os objetivos estratégicos estão sendo alcançados ou não. Do mesmo modo também aponta qual a maneira mais segura, ou onde devem ser concentrados os esforços para que elas se tornem mais produtivas. Para a parte operacional, segundo autores japoneses, trata-se de uma atitude do coração.

Podem ser empregados indicadores de produtividade como ferramenta de medição e análise do valor agregado, uma vez que há uma relação direta entre ambos, Cardoso (2001).

Neely et al. (2000), descrevem o desenho de um sistema de medidas de desempenho de doze fases: o que medir, análise de custo beneficio, propósito da medida, compreensão, estrutura de cada medida de desempenho, integração, considerações do ambiente, inter-funcionalidade, considerações inter-funcionais com relação ao ambiente, testes do número máximo de desempenho, institucionalização, manutenção dos indicadores redundantes.

Kaplan e Norton (1992), por sua vez, estabeleceram uma ligação em quatro dimensões para o sistema de medidas de desempenho, conforme o balanced scorecard: perspectiva financeira, perspectiva do consumidor, perspectiva de inovação e aprendizado e perspectiva interna do negócio. Não se pode negar que há uma relação estreita com a forma de custeio aplicado e, também, que essas perspectivas relacionam indicadores financeiros e não financeiros.

Cardoso (2001) demonstra um rol de indicadores, expostos conforme o quadro 2 abaixo, que expressam o valor agregado e uma dinâmica metodológica para a medição. Neste quadro podese observar os conjuntos de indicadores propostos. O conjunto de indicadores de produtividade 
busca avaliar a organização quanto as maneiras de emprego dos equipamentos e a mão de obra. O grupo de indicadores de crescimento proporciona a analise da situação da organização relacionada com o seu crescimento. Enquanto que os indicadores de rentabilidade buscam expressar o desempenho da rentabilidade do negócio. Por ultimo, o conjunto de indicadores de segurança medem a saúde financeira da empresa.

Quadro 2 - Indicadores de Medição do Valor Agregado

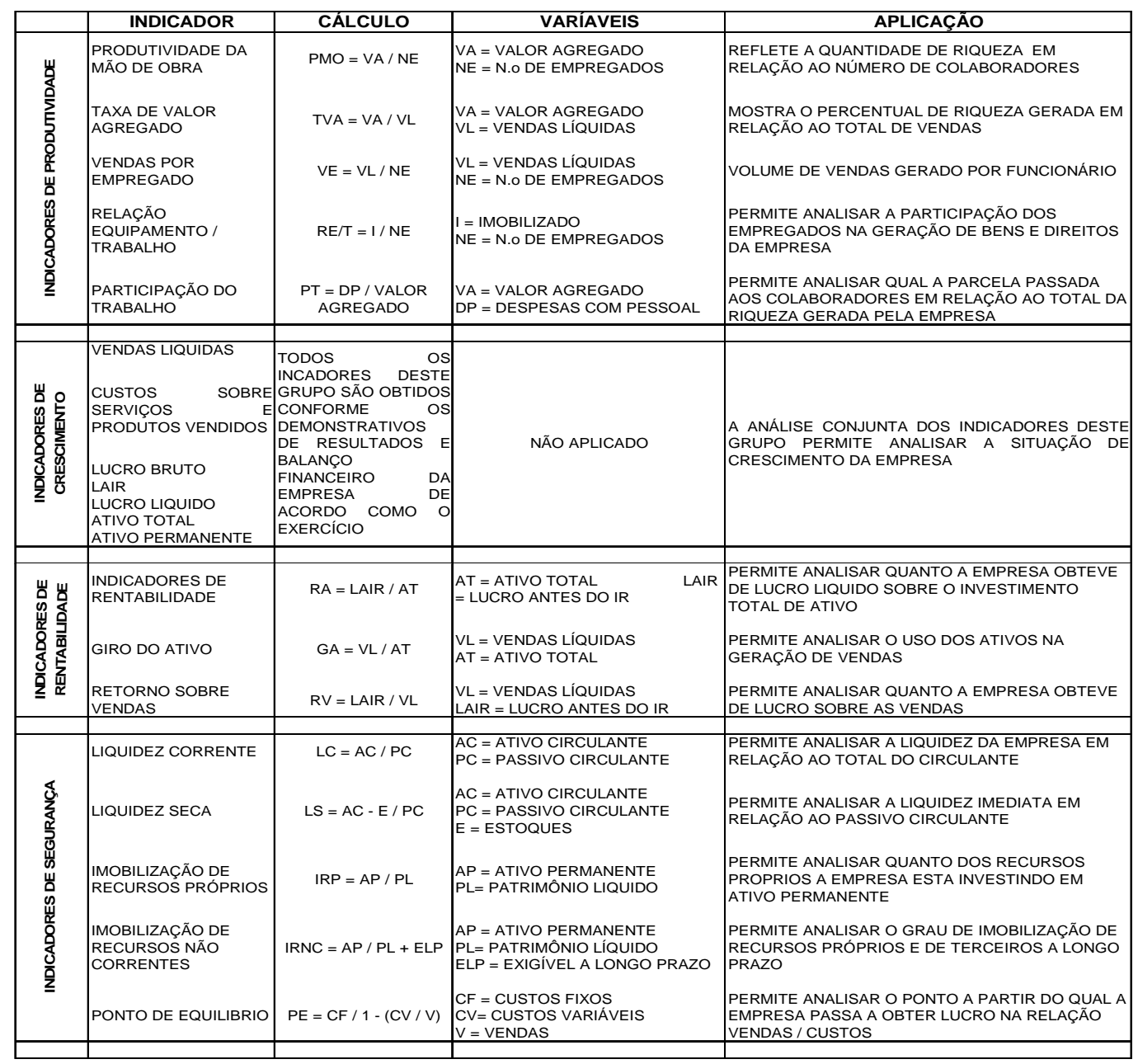

Fonte - Adaptada: Cardoso Metodologia para Medição e Análise da Produtividade a Partir do Valor Agregado. 2001.

Embora, a relação de indicadores apresentados, tem uma forte expressão contábil no conjunto é possível empregá-los de maneira gerencial, cujas informações podem se transformar em ações enriquecendo a gestão operacional. 


\section{Conclusão}

A revisão bibliográfica realizada neste trabalho reuniu, inicialmente, conceitos que englobaram vários aspectos relacionados entre si que demonstram a adoção da produtividade atuando como vetor facilitador para a formação do valor agregado em produtos ofertados para o mercado em geral. Demonstra também que não há uma resposta direta sobre a relação da produtividade $\mathrm{x}$ valor agregado nos processos de manufatura, pois a produtividade se revela como resultado de um conjunto de fatores originados pela definição e aplicação das políticas e sistemas de operações.

Para tanto, o exame e a contribuição de vários autores, proporcionou como resultado final um composto analítico, adequando os aspectos avaliados, cuja linha de raciocínio ficará estabelecida como um roteiro. Este roteiro teve origem na compreensão do processo da competição e no estabelecimento do processo estratégico, direcionando-se para a construção dos contextos do planejamento onde a manufatura se destacou como figura principal, pois é a origem da produtividade, do valor agregado e das medidas de desempenho.

Em concordância com este composto analítico conclui-se que, a competição se dá quase concomitantemente com a estratégia. Portanto, a estratégia passa a ser um processo integrador e direcionador que tem como premissa interligar as funcionalidades organizacionais no sentido de proporcionar a elaboração de vantagens únicas. Complementando, a manufatura é tratada como o núcleo de transformação do processo sistêmico de produção que tem como apoio a função de planejamento e controle de produção. Esta relação expressa certo grau de relevância, uma vez que, ela originará subsídios suficientes para a execução do plano de produção com base na capacidade do processo, e por fim, de aferição dos resultados traduzidos como produtividade. Finalmente o entendimento da formação do valor originado da função da manufatura, estabelece que todo negócio, em principio, cria valor como conseqüência de suas atividades levando em conta também o comportamento do fator humano. Ficou evidente que a participação do fator humano é função preponderante para a formação do valor agregado, uma vez que este fator se destaca na formação e propagação da cultura organizacional.

Enfim, este trabalho proporcionou o encadeamento de um conjunto de assuntos em coerência com o ambiente organizacional da atualidade, deixando espaço suficiente para a exploração de outras possibilidades de estudo. Espera-se que esta pesquisa possa contribuir para futuras pesquisas no sentido de se buscar o grau de consciência disseminado nas estruturas organizacionais para a pratica da alta produtividade como fator de geração de riqueza ou valor 
agregado.

\begin{abstract}
This paper aims at investigating the use of productivity programs as a facilitating way for making up the value of products which are offered in the market. Besides it also shows an alternative way to visualize the existing relation of cause and effect.

Thus several authors were studied resulting in a final analytical compound which may adequately represent the evaluated aspects.

It was concluded that there still is a considerable field to show that added value is also the result of an organizational culture. It was also concluded that there are several other possibilities of studies which have not yet been observed and which deserve a deeper view in future researches.
\end{abstract}

Key-words: Productivity; Value Added; Manufacturing Management.

\title{
7. Referências
}

BONNEY, Maurice. Reflections on productions planning and control (PCP). Gestão \& Produção, v. 7 n. 3. São Carlos, São Paulo: dec. 2000.

CAMPOS, Vicente F. Controle da Qualidade Total: No estilo japonês. 2.a edição, Minas Gerais: editora Bloch, 1992.

CARDOSO; Willy K. Metodologia para Medição e Análise da Produtividade a Partir do Valor Agregado. 2001.45 f. Dissertação para obtenção do titulo de Mestre em Engenharia - Universidade Federal de Santa Catarina. Florianópolis, Santa Catarina.

CAVENAGHI, Vagner. Gestão do desempenho empresarial: A contribuição da área de manufatura. 2001.119 f. Tese de Doutorado em Engenharia - Escola Politécnica da Universidade de São Paulo, São Paulo.

CONTADOR, José C. Modelos pra aumentar a competitividade Industrial: A transição para a gestão participativa. 1.a edição, São Paulo: editora Edgard Blucher, 1996.

CORRÊA, Henrique L; GIANESI, Irineu G.N; CAON, Mauro: Planejamento, Programação e Controle de Produção MRP II / ERP: Conceitos, uso e implantação. 4.a ed., São Paulo: editora Atlas, 2001.

CORRÊA, Henrique L; CORRÊA, Carlos A. Administração de Produção e Operações Manufatura e Serviços: Uma abordagem estratégica. 2. a edição, São Paulo: editora Atlas, 2006.

DE LUCA, Márcia M. M. Demonstração do valor adicionado. São Paulo: editora Atlas, 1998.

FUSCO José Paulo Alves. Unidades estratégicas de negócio - uma ferramenta para gestão competitiva de empresas. Gestão \& Produção. v 4, n. 1, p. 36 - 51, abr. 1997.

FUSCO, José Paulo Alves; SACOMANO José Benedito; BARBOSA Fábio Alves; JUNIOR Walther Azzolini. Administração de operações: Da formulação estratégica ao controle operacional. 1.a edição, v 1, São Paulo: editora Arte e Ciência, 2003.

HAYES, Robert H.; WHEELWRIGHT, Steven C. Restoring our competitive edge: competing through manufacting. New York: John Wiley \& Sons, p. 28. 1984.

HENDERSON, Bruce D. The origin of strategy. Harward Busines Review, o 139 - 143, Dakota South: nov.- dec. 1989.

KAPLAN, Robert S; NORTON, David P. The balanced scorecard - Measures that drive performance. Harward Busines Review, jan. - feb. 1992.

LAKATOS, Eva M; MARCONI, Marina A. Fundamentos da metodologia científica. 5.a MARTINS, Eliseu. Uma nova demonstração contábil: a do "valor adicionado”. Temática Contábil e Balanços. Boletim IOB 11 - 1989, p. 98.

edição, São Paulo: editora Atlas, 2003. 
MARTINS, Roberto A. Sistemas de medição de desempenho: Um modelo para estruturação do uso. 1999.128 f. Tese de Doutorado em Engenharia - Escola Politécnica da Universidade de São Paulo, São Paulo.

MOREIRA, Daniel A.: Dimensões do desempenho em manufatura e serviços. 1.a edição, São Paulo: editora Pioneira, 1996.

NEELY Andy; MILLS John; RICHARDS Huw; GREGORY Mike; BOURNE Mike; KENNERLEY Mike.. Performance measurement system design: developing and testing a process-based approach. International Journal of Operations \& Production Management. v. 20, n. 10, p. 1119 - 1145. UK: 2000.

PAROLINI, Cintia. The net value: A tool for competitive strategy.Chichester: editora John Willey and Sons, 1999.

PORTER Michael. Estratégia Competitiva: Técnicas para análise de indústrias e da concorrência. 1.a edição, São Paulo: editora Campus, 1986.

Estratégia: a busca da vantagem competitiva. Rio de Janeiro: editora Campus, 1998.

SANTORO, Miguel C; FERNANDES Flavio C. F. Avaliação do grau de prioridade e do foco do planejamento e controle da produção (PCP): Modelos e estudos de caso. Gestão \& Produção, v. 12, n. 1, p. 23-38. São Carlos, São Paulo: jan. - abr. 2005.

SKINNER, Wickham. Manufaturing: missing link in corporate strategy. Harward Business Review. USA: p 136 - 145 , may-june 1969.

SLACK, Nigel; CHAMBERS Stuart; JOHNSTON Robert. Administração da Produção. 2.a edição, São Paulo: editora Atlas, 2002.

\section{Dados do primeiro autor:}

Nome completo: Wagner Boer

Instituição: FEB UNESP - Faculdade de Engenharia de Bauru - Universidade Estadual de São Paulo Julio de Mesquita

Departamento: Engenharia de Produção

Função: Aluno Regular do Programa de Mestrado

Endereço: Rodovia Domingos Sartori, km 1 n.o 716, Jardim Europa, Botucatu, São Paulo, Brasil , CEP 18607621

Fone: 014 - 97189081

Email: wagner.boer@embraer.com.br 